\title{
Impact of heat treatment on size, structure, and bioactivity of elemental selenium nanoparticles
}

\author{
This article was published in the following Dove Press journal: \\ International Journal of Nanomedicine \\ 16 February 2012 \\ Number of times this article has been viewed
}

\section{Jinsong Zhang' \\ Ethan W Taylor ${ }^{2}$ \\ Xiaochun Wan' \\ Dungeng Peng ${ }^{3}$}

'School of Tea and Food Science, Anhui Agricultural University, Anhui, People's Republic of China; ${ }^{2}$ Department of Nanoscience, Joint School of Nanoscience and Nanoengineering, University of North Carolina at Greensboro, Greensboro, NC, ${ }^{3}$ Department of Biochemistry, Vanderbilt University, Nashville, TN, USA
Correspondence: Jinsong Zhang School of Tea and Food Science, Anhui Agricultural University, Hefei 230036, Anhui, People's Republic of China

Tel +865515786283

Fax +86 55I 5786283

Email zjs@ahau.edu.cn

Dungeng Peng

Department of Biochemistry,

Vanderbilt University, Nashville,

TN 37232, USA

Email dgpeng@gmail.com
Background: Elemental selenium nanoparticles have emerged as a novel selenium source with the advantage of reduced risk of selenium toxicity. The present work investigated whether heat treatment affects the size, structure, and bioactivity of selenium nanoparticles.

Methods and results: After a one-hour incubation of solution containing $80 \mathrm{~nm}$ selenium particles in a $90^{\circ} \mathrm{C}$ water bath, the nanoparticles aggregated into larger $110 \mathrm{~nm}$ particles and nanorods $(290 \mathrm{~nm} \times 70 \mathrm{~nm})$, leading to significantly reduced bioavailability and phase II enzyme induction in selenium-deficient mice. When a solution containing $40 \mathrm{~nm}$ selenium nanoparticles was treated under the same conditions, the nanoparticles aggregated into larger $72 \mathrm{~nm}$ particles but did not transform into nanorods, demonstrating that the thermostability of selenium nanoparticles is size-dependent, smaller selenium nanoparticles being more resistant than larger selenium nanoparticles to transformation into nanorods during heat treatment.

Conclusion: The present results suggest that temperature and duration of the heat process, as well as the original nanoparticle size, should be carefully selected when a solution containing selenium nanoparticles is added to functional foods.

Keywords: nanoparticle, selenium, bioactivity, heat treatment

\section{Introduction}

Selenium has multiple beneficial effects for human health, through regulation of at least 25 selenoproteins all containing selenocysteine, the 21 st genetically encoded protein amino acid. ${ }^{1}$ Among these selenoproteins, the glutathione peroxidase and thioredoxin reductase families are well characterized. Glutathione peroxidases catalyze the reduction of hydrogen peroxide and a variety of organic hydroperoxides, including phospholipid hydroperoxide, to water and corresponding alcohols, using glutathione as the hydrogen donor. ${ }^{2}$ Thioredoxin reductases exert antioxidant actions through catalyzing the reduction of oxidized thioredoxin, using nicotinamide-adenine dinucleotide phosphate (NADPH) as the electron donor, or by directly reacting with hydrogen peroxide and hydroperoxides. ${ }^{3}$ Variations in selenoprotein genes have been found to be associated with increased cancer risk. ${ }^{4,5}$ Transgenic mice with reduced selenoprotein expression manifest precancerous changes. ${ }^{6,7}$ Human studies have shown reduced cancer risk and DNA damage after selenium supplementation among those with lower basal plasma selenium. ${ }^{8-10}$ These studies argue for a cancer-preventive effect of selenium at nutritional levels in selenium-deficient populations.

Like various other naturally occurring chemopreventive agents, such as sulforaphane, curcumin, resveratrol, and epigallocatechin gallate, selenium at supranutritional levels (which are roughly 10-30-fold higher than nutritional levels) is also capable of 
inducing phase II detoxification enzymes, such as glutathione S-transferase and quinone reductase. ${ }^{11-15}$ The resulting enhanced detoxification many contribute to the powerful chemopreventive effects exhibited by supranutritional selenium, which have been observed in approximately 100 small animal studies. ${ }^{8,16,17}$ Since supranutritional selenium levels are close to the toxic selenium levels in general, ${ }^{8,16,17}$ the safety margin and potential toxic effects of different selenium compounds are critical considerations when evaluating their potential for supplementation.

Bulk red elemental selenium particles at the redox state of zero found in some bacteria are biologically inert. ${ }^{18}$ It is known that elemental selenium atoms can be formed in the redox system of sodium selenite and glutathione at the molar ratio of 1:4. ${ }^{19}$ We have demonstrated that the presence of a protein such as bovine serum albumin in the redox system can control the aggregation of neonatal elemental selenium atoms, thus inhibiting the formation of bulky red elemental selenium particles, and consequently leading to the formation of red elemental selenium nanoparticles. ${ }^{20}$ Compared with several extensively studied selenium compounds, ie, sodium selenite, selenomethionine, and methylselenocysteine, selenium nanoparticles show markedly lower acute toxicity and significantly lower short-term and subchronic toxicities, but all these selenium compounds have equivalent efficacy in their ability to increase selenoenzymes. ${ }^{20-25}$ Furthermore, selenium nanoparticles appear to be more efficient than sodium selenite and selenomethionine in increasing glutathione S-transferase activity, ${ }^{21,25}$ and seem to be equally efficient in inducing apoptosis of certain types of cancer cells as methylseleninic acid, a metabolite of methylselenocysteine that is considered to be the most promising selenium compound in cancer prevention. ${ }^{26}$ Selenium nanoparticles may enhance selenium permeation and retention in tumor tissues because their blood vessels contain enlarged pore sizes ranging from $100 \mathrm{~nm}$ to $800 \mathrm{~nm}$, in stark contrast with the pore sizes of $2 \mathrm{~nm}$ to $6 \mathrm{~nm}$ in the vessels of healthy tissues. ${ }^{27} \mathrm{In}$ addition to cancer prevention, selenium nanoparticles also show potential as antimicrobial agents. ${ }^{28}$

Selenium nanoparticles have emerged as a novel selenium source with the obvious advantage of reduced risk of selenium toxicity. ${ }^{20-25,29,30}$ Accordingly, a selenium nanoparticle solution may be added to functional foods, the final products of which may be subjected to heat during processing. An important feature of nanoparticles is their high surface to volume ratio. As the nanosize decreases, surface atomicity, surface energy, and surface binding energy all increase quickly; as a result, the surface atoms become more prone to diffusion, with an inherent tendency to combine with other atoms for energy dissipation. Hence, the thermodynamic properties and stability of nanoparticles should be affected by particle size and heat treatment. ${ }^{31-33}$ The thermal stability of selenium nanoparticles as a type of nanoscale biomaterial remains unknown. Herein, we investigated the impact of heat treatment on the size, structure, and bioactivity of selenium nanoparticles. We found that heat treatment causes selenium nanoparticles to aggregate into larger sizes and nanorods, leading to significantly reduced bioactivity in mice. The thermostability of selenium nanoparticles is size-dependent, smaller selenium nanoparticles being more resistant than larger selenium nanoparticles to transformation into nanorods during heat treatment.

\section{Materials and methods Chemicals}

NADPH, dithio-bis-nitrobenzoic acid, glutathione, 4-(2-Hydroxyethyl)-1-piperazineethanesulfonic acid (HEPES), insulin, thioredoxin (Escherichia coli), guanidine hydrochloride, bovine serum albumin, 1-chloro-2,4-dinitrobenzene, and 2,3-diaminonaphthalene were all purchased from Sigma (St Louis, MO). Other chemicals, including hexamethylene, hydroxylamine hydrochloride, nitric acid, and perchloric acid, were of the highest grade available.

\section{Solution-based preparations of selenium nanoparticles of two sizes}

One $\mathrm{mL}$ of $25 \mathrm{mM}$ sodium selenite was mixed with $4 \mathrm{~mL}$ $25 \mathrm{mM}$ of glutathione containing either $2 \mathrm{mg}$ or $20 \mathrm{mg}$ bovine serum albumin. The mixture $\mathrm{pH}$ was adjusted to 7.2 with 1.0 M sodium hydroxide to generate red elemental selenium and oxidized glutathione. ${ }^{20}$ The red solution was dialyzed for 96 hours at $4^{\circ} \mathrm{C}$ against double distilled water which was replaced every 24 hours to separate oxidized glutathione from the selenium nanoparticles. The final solution containing selenium nanoparticles and bovine serum albumin was stored in a $4^{\circ} \mathrm{C}$ refrigerator, in which the selenium nanoparticle solution prepared using the low concentration of bovine serum albumin was stable for several months, and the selenium nanoparticle solution prepared by using the high concentration of bovine serum albumin was stable for several years.

\section{Nanoparticle observation}

A droplet of selenium nanoparticle solution was dropped onto copper grids and allowed to dry in air before observation under a high resolution transmission electron microscope. The average sizes of selenium nanoparticles prepared using 
the low and high concentrations of bovine serum albumin were $80 \mathrm{~nm}(45 \mathrm{~nm} \sim 95 \mathrm{~nm})$ and $40 \mathrm{~nm}(20 \mathrm{~nm} \sim 55 \mathrm{~nm})$, respectively.

\section{Animals and treatments}

Selenium-deficient male Kunming mice (21-22 g) and their selenium-deficient diet were all purchased from the animal center in Anhui Medical University. The mice were housed in plastic cages in a room with controlled temperature $\left(22^{\circ} \mathrm{C} \pm 1{ }^{\circ} \mathrm{C}\right)$ and humidity $(50 \% \pm 10 \%)$ on a 12 -hour light/dark cycle. The mice were allowed to obtain food and water ad libitum. All experiments involving the mice were performed in compliance with the ethical guidelines issued by the Anhui Agriculture University.

\section{Nutritional level of selenium}

In the bioavailability experiment, 15 mice were divided into three groups $(n=5)$ : the control group was administered oral saline; the other two groups were orally given selenium nanoparticles, either unheated or heated, at a selenium dose of $100 \mu \mathrm{g} / \mathrm{kg}$ body weight for 7 days.

\section{Supranutritional level of selenium}

In the supranutritional dose experiment, 24 mice were divided into three groups $(n=8)$ : the control group was administered oral saline; the other two groups were administered oral selenium nanoparticles, either unheated or heated, at a selenium dose of $2000 \mu \mathrm{g} / \mathrm{kg}$ body weight for 7 days.

\section{Biomarkers}

At the end of each set of experiments, the mice were sacrificed by cervical dislocation. Peripheral blood from the ophthalmic veins was collected into tubes to obtain blood and plasma after centrifugation. The livers were excised immediately and rinsed in ice-cold saline. The samples were stored at $-30^{\circ} \mathrm{C}$ before assay. Liver tissues were homogenized in ice-cold $150 \mathrm{mM}$ and $\mathrm{pH} 7.2$ phosphate-buffered saline containing $1 \mathrm{mM}$ EDTA-Na $2(1: 9, \mathrm{w} / \mathrm{v})$, and the homogenate was then centrifuged at $15,000 \mathrm{~g}$ and $4^{\circ} \mathrm{C}$ for 15 minutes. The resulting supernatants were used for determination of soluble protein levels with bovine serum albumin as standard, ${ }^{34}$ and for determination of glutathione peroxidase, thioredoxin reductase, and glutathione S-transferase activity.

\section{Glutathione peroxidase activity assay}

Glutathione peroxidase was assayed using the method of Rotruck et al. ${ }^{35}$ Glutathione peroxidase activity was expressed as units/mg protein or units/mL plasma; one unit of the activity was calculated in terms of $1 \mu \mathrm{mol}$ of glutathione oxidized per minute.

\section{Glutathione S-transferase activity assay}

Glutathione S-transferase activity was chemically determined at $340 \mathrm{~nm}$ using 1-chloro-2,4-dinitrobenzene as the substrate. Glutathione S-transferase activity was expressed as units/ minute/mg protein; one unit of activity was calculated in terms of nmol of 1-chloro-2,4-dinitrobenzene changed per minute. ${ }^{36}$

\section{Thioredoxin reductase activity assay}

Thioredoxin reductase activity was measured based on the method of Holmgren and Björnstedt ${ }^{37}$ with some modifications. A stock mixture was composed of HEPES buffer (1.0 M, pH 7.6), EDTA (0.2 M), NADPH (40 mg/mL), and bovine insulin $(10 \mathrm{mg} / \mathrm{mL})$ in a volume ratio of 5:1:1:12.5. In a 96 -well plate, $3 \mu \mathrm{L}$ thioredoxin $(2 \mathrm{mg} / \mathrm{mL})$, $7 \mu \mathrm{L}$ stock mixture, $40 \mu \mathrm{L}$ HEPES (50 mM, pH 7.6), and $20 \mu \mathrm{L}$ liver homogenate (with $20-30 \mu \mathrm{g}$ protein) were added to each well. The enzymatic reaction was maintained at $37^{\circ} \mathrm{C}$ for 20 minutes, and then terminated by adding $240 \mu \mathrm{L}$ stop solution containing $0.2 \mathrm{mg} / \mathrm{mL}$ dithio-bis-nitrobenzoic acid, $6 \mathrm{M}$ guanidine hydrochloride, and 0.2 M Tris at $\mathrm{pH}$ 8.0. Each sample contained a nonenzymatic reaction as the control. The nonenzymatic reaction included all components except thioredoxin, which was replaced by the same volume of saline. The 96-well plates were read at $412 \mathrm{~nm}$. The absorbance of the control was subtracted from the absorbance of the sample. A background control, which was the subtraction of absorbance with and without thioredoxin in the absence of liver homogenate, was further subtracted from all samples. Thioredoxin reductase activity unit was defined as A412 change $\times 1000$ per minute and thioredoxin reductase activity was expressed as $\mathrm{U} / \mathrm{mg}$ protein. ${ }^{38}$

\section{Selenium assay}

Selenium was assayed by a fluorescence method. ${ }^{39}$ Samples were digested using the mixture of nitric acid and perchloric acid at the ratio of $3: 1(\mathrm{v} / \mathrm{v})$, then reacted with 2,3-diaminonaphthalene at $60^{\circ} \mathrm{C}$ for 30 minutes, then finally extracted with hexamethylene. The fluorescence intensity excited at $378 \mathrm{~nm}$ and recorded at $512 \mathrm{~nm}$ was used for calculating selenium concentration with sodium selenite as a standard.

\section{Statistical analysis}

Data are presented as the mean \pm standard error of the mean. The differences between groups were examined by one-way 
analysis of variance post hoc Tukey test, using GraphPad Software (Prism version 5, San Diego, CA). $P<0.05$ was considered to be statistically significant.

\section{Results}

\section{Impact of heat treatment}

Size and structure of $80 \mathrm{~nm}$ selenium nanoparticles

A sealed glass tube with $10 \mathrm{~mL}$ of the $80 \mathrm{~nm}$ selenium nanoparticle solution was incubated in a $1000 \mathrm{~mL}$ water bath at $90^{\circ} \mathrm{C}$ for one hour, and then the hot glass tube was cooled in an ice bath to room temperature. Under inspection by high resolution transmission electron microscopy, it was found that the selenium nanoparticles changed substantially due to heat treatment. As shown in Figure 1A, selenium particles in the precursor unheated selenium nanoparticle solution were spherical nanoparticles with an average size of $80 \mathrm{~nm}$ ranging from $45 \mathrm{~nm}$ to $95 \mathrm{~nm}$, whereas in the heated selenium nanoparticle solution (Figure 1B), the precursor selenium nanoparticles were replaced by both enlarged nanoparticles with an average size of $110 \mathrm{~nm}$ ranging from $70 \mathrm{~nm}$ to $120 \mathrm{~nm}$ and nanorods, the average dimension of which was $290 \mathrm{~nm} \times 70 \mathrm{~nm}$.

\section{Bioavailability of $80 \mathrm{~nm}$ selenium nanoparticles}

The primary purpose of this study was to investigate the impact of heat treatment on the bioactivity of selenium nanoparticles. One of the most fundamental properties of selenium compounds is bioavailability in terms of increasing selenoenzyme activity and tissue selenium levels. We have shown that oral administration of selenium nanoparticles to selenium-deficient mice at doses of 35, 70, and $1000 \mu \mathrm{g} / \mathrm{kg}$ for one week dose-dependently increased selenoenzyme activity and tissue selenium levels. ${ }^{21}$ Thus, in the present study, we used selenium $100 \mu \mathrm{g} / \mathrm{kg}$, which is a typical selenium nutritional dose, for one-week oral supplementation. As compared with the control (Figure 2A),

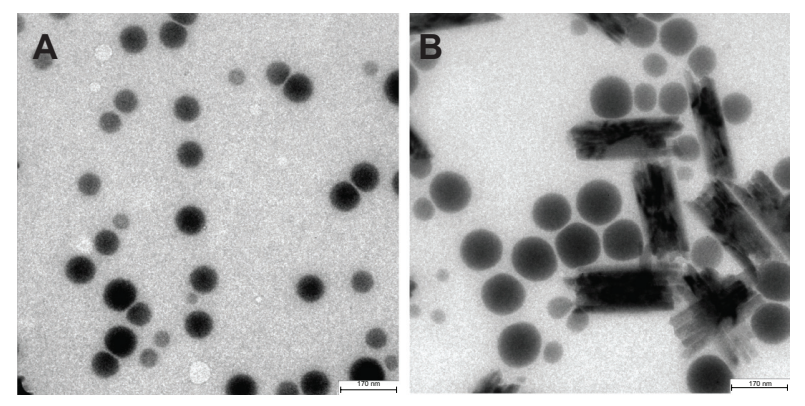

Figure I Heat treatment changes the size and the structure of $80 \mathrm{~nm}$ selenium nanoparticles. (A) Unheated precursor selenium nanoparticles. (B) Precursor selenium nanoparticle solution after heating at $90^{\circ} \mathrm{C}$ for one hour.

Note: The bar in A and $\mathbf{B}$ represents $170 \mathrm{~nm}$. the unheated $80 \mathrm{~nm}$ selenium nanoparticles significantly $(P<0.001)$ increased hepatic glutathione peroxidase activity by 5.7 -fold, whereas the heated selenium nanoparticles significantly increased the activity $(P<0.01)$, but only by 3.0-fold; accordingly, a significant difference $(P<0.01)$ existed between the two selenium nanoparticle groups. As compared with the control (Figure 2B), the unheated $80 \mathrm{~nm}$ selenium nanoparticles significantly $(P<0.01)$ increased hepatic thioredoxin reductase activity by 1.9 -fold. In contrast, the heated selenium nanoparticles did not significantly alter the activity; consequently, a significant difference $(P<0.01)$ existed between the two selenium nanoparticle groups. As compared with the control (Figure 2C), the unheated $80 \mathrm{~nm}$ selenium nanoparticles significantly $(P<0.001)$ increased hepatic selenium by 2.0 -fold, whereas the heated selenium nanoparticles significantly $(P<0.05)$ increased the selenium level, but only by 1.5 -fold; accordingly, a significant difference $(P<0.05)$ existed between the two selenium nanoparticle groups. As compared with the control (Figure 2D), the unheated $80 \mathrm{~nm}$ selenium nanoparticles significantly $(P<0.001)$ increased plasma glutathione peroxidase activity by 2.3 -fold, whereas the heated selenium nanoparticles significantly $(P<0.01)$ increased the activity, but only by 1.7-fold; accordingly, a significant difference $(P<0.05)$ existed between the two selenium nanoparticle groups. Coincidentally, plasma selenium levels almost completely mirrored the alterations found in plasma glutathione peroxidase (Figure 2D). These results clearly demonstrate that the heat treatment significantly reduced bioavailability of the $80 \mathrm{~nm}$ selenium nanoparticles.

\section{Glutathione S-transferase induction}

\section{and selenium retention of $80 \mathrm{~nm}$ nanoparticles}

\section{at a supranutritional level}

Another important bioactivity of selenium, in addition to bioavailability, is its impact on phase II enzymes. We have shown that oral administration of selenium nanoparticles to selenium-deficient mice at supranutritional selenium doses of 500 and $2000 \mu \mathrm{g} / \mathrm{kg}$ for one week dose-dependently increased glutathione S-transferase activity and tissue selenium levels. ${ }^{40}$ Thus, in the present study, we used selenium $2000 \mu \mathrm{g} / \mathrm{kg}$ for one week as oral supplementation. As compared with the control (Figure 3A), the unheated $80 \mathrm{~nm}$ selenium nanoparticles significantly $(P<0.001)$ increased hepatic glutathione S-transferase activity by 1.6 -fold. In contrast, heated $80 \mathrm{~nm}$ selenium nanoparticles did not alter the activity; consequently, a significant difference $(P<0.001)$ existed between the two selenium nanoparticle groups. As compared 

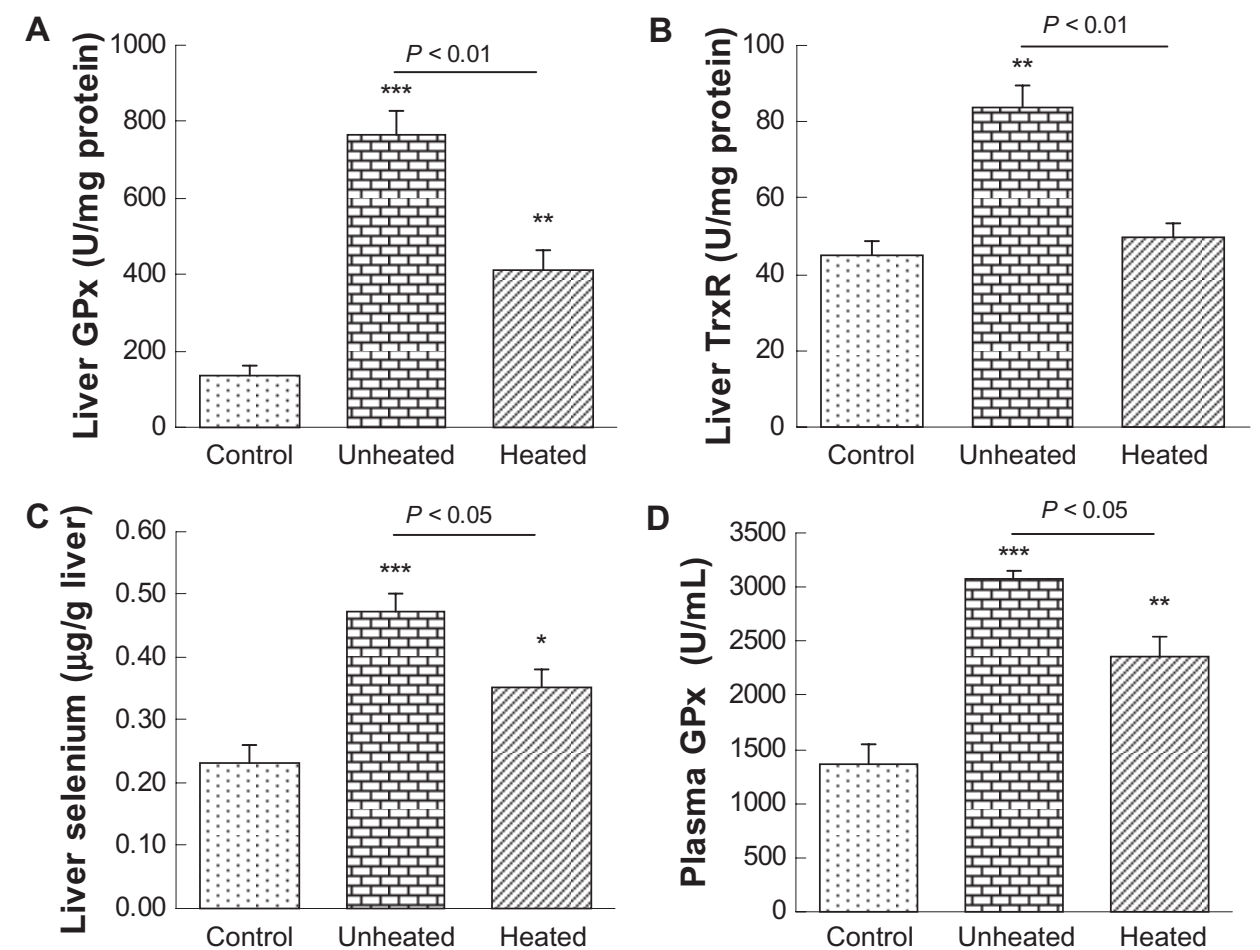

E

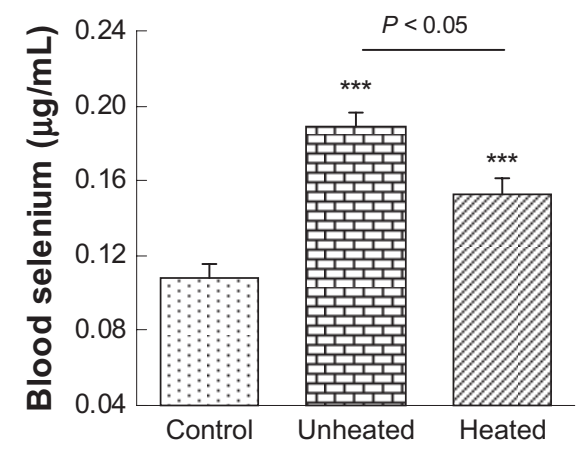

Figure 2 Heat treatment reduces bioavailability of $80 \mathrm{~nm}$ selenium nanoparticles at a nutritional level. Selenium-deficient mice were orally administered with saline as a control, or $80 \mathrm{~nm}$ selenium nanoparticles, either unheated or heated, at a selenium dose of $100 \mu \mathrm{g} / \mathrm{kg}$ for 7 days.

Notes Compared with the controls, *P<0.05; **P $<0.0$ I; ***P $<0.001$.

Abbreviations: GPx, glutathione peroxidase; TxR, thioredoxin reductase.

with the control (Figure 3B), the unheated $80 \mathrm{~nm}$ selenium nanoparticles significantly $(P<0.001)$ increased hepatic selenium by 8.9 -fold, whereas the heated selenium nanoparticles significantly $(P<0.001)$ increased the selenium levels, but only by 6.6 -fold; accordingly, a significant difference $(P<0.001)$ existed between the two selenium nanoparticle groups. As compared with the control (Figure 3C), both the unheated and the heated selenium nanoparticles caused a highly significant (all $P<0.001$ ) massive increase in hepatic glutathione peroxidase activity, by 38.8-fold and 34.2-fold, respectively. However, as expected, no significant differences were found between the two selenium nanoparticle groups, because selenoenzymes, including hepatic glutathione peroxidase, can be fully saturated at the upper end of nutritional selenium levels. Although the heated $80 \mathrm{~nm}$ selenium nanoparticles showed an approximately $50 \%$ reduced efficacy in increasing hepatic glutathione peroxidase activity at $100 \mu \mathrm{g}$ selenium $/ \mathrm{kg}$ as compared with the unheated material (Figure 2A), in this case a 20-fold increase of selenium amounts should fully compensate for this defect.

\section{Size and structure of $40 \mathrm{~nm}$ selenium nanoparticles}

The $40 \mathrm{~nm}$ selenium nanoparticles were treated with heat under the same conditions and for the same duration as the $80 \mathrm{~nm}$ selenium nanoparticles. Under inspection by high resolution transmission electron microscopy, as shown in Figure 4A, the selenium particles in the unheated selenium nanoparticle solution were spherical, with an average size of 


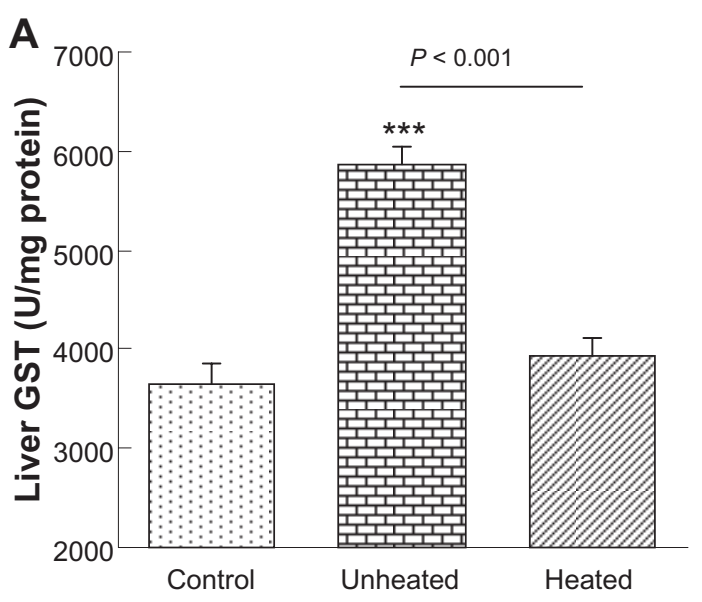

B
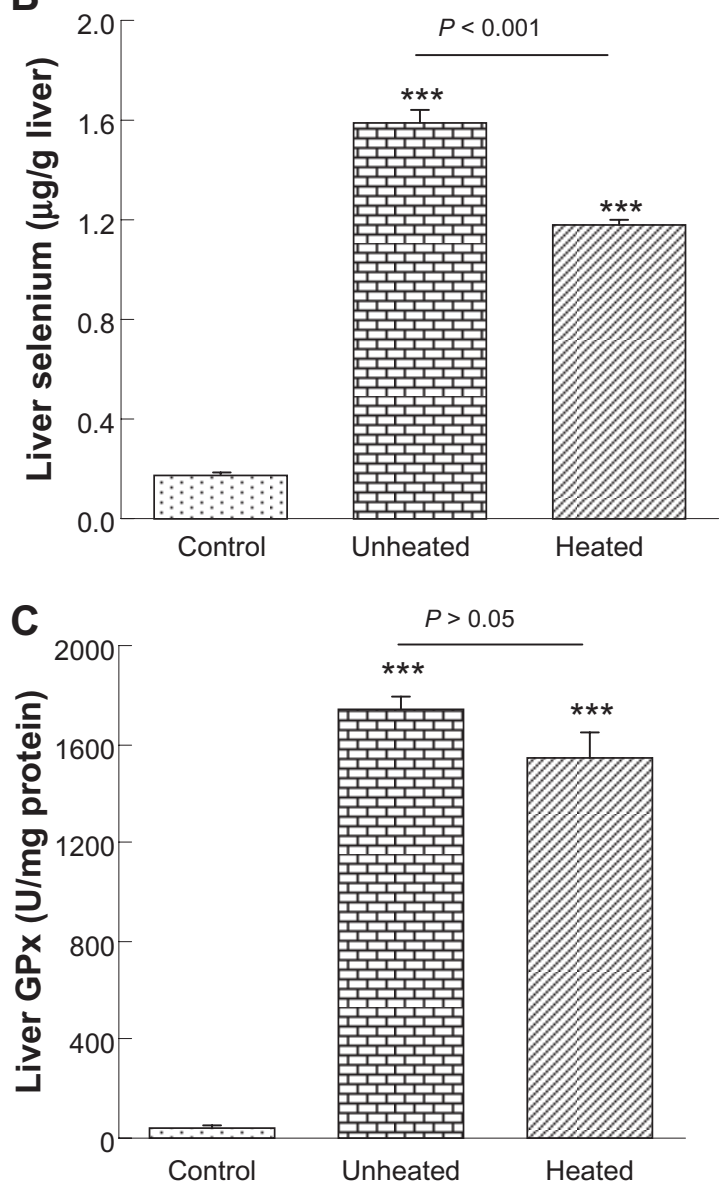

Figure 3 Heat treatment reduces the bioactivity of $80 \mathrm{~nm}$ selenium nanoparticles at a supranutritional level. Selenium-deficient mice were orally administered with saline as a control, or $80 \mathrm{~nm}$ selenium nanoparticles, either unheated or heated, at selenium dose of $2000 \mu \mathrm{g} / \mathrm{kg}$ for 7 days.

Note: Compared with the controls, *** $P<0.001$.

Abbreviations: GST, glutathione; GPx, glutathione peroxidase.

$40 \mathrm{~nm}$, ranging from $20 \mathrm{~nm}$ to $55 \mathrm{~nm}$, whereas in the heated selenium nanoparticle solution (Figure 4B), enlarged nanoparticles with an average size of $70 \mathrm{~nm}$ were observed. In stark contrast with heat-activated evolution of the $80 \mathrm{~nm}$ selenium nanoparticles, in this case nanorods were not observed.
Strikingly, the enlarged selenium nanoparticles had a surprisingly narrow size distribution ranging from $68 \mathrm{~nm}$ to $72 \mathrm{~nm}$, highly faceted morphology, and uniform edge-to-edge distances between particles relative to the untreated precursor nanoparticles (Figure 4A and B). These contrasts could be more clearly seen from the photos with enhanced resolution (Figure 4C for the unheated selenium nanoparticles and Figure 4D for the heated selenium nanoparticles).

\section{Discussion}

Elemental selenium nanoparticles can be formed naturally in certain bacteria, ${ }^{41-43}$ and can be prepared through inorganic selenium reduction in the presence of protein or polysaccharide. ${ }^{20,44-46}$ Various sizes of selenium nanoparticles can be obtained by changing the concentration of a protein such as bovine serum albumin. ${ }^{47,48}$ Generally, the higher the bovine serum albumin concentration, the smaller the selenium nanoparticle size. ${ }^{47,48}$ Accordingly, in the present study, $40 \mathrm{~nm}$ and $80 \mathrm{~nm}$ selenium nanoparticles were prepared by adding low or high concentrations of bovine serum albumin to the redox system of sodium selenite and glutathione.

Nanoparticles have an inherent tendency to grow into larger particles. In general, a smaller nanoparticle with a lower melting point grows uniformly, until it becomes stable at a specific heat treatment temperature through thermodynamic control. ${ }^{32,33}$ Maye et al and Maye and Zhong, have investigated the effect of heat treatment on the manipulation of the size and shape of alkanethiol-protected gold nanoparticles in solution..$^{32,33}$ The precursor gold nanoparticles they used showed an average core size of $2.0 \mathrm{~nm}$ with a wide size distribution; in addition, the particle shapes were not uniform. After heat treatment, the sizes of gold nanoparticles increased, and, in sharp contrast with the morphological features of the precursor nanoparticles, the enlarged nanoparticles evolved from heat treatment showed three striking features, ie, a much narrower size distribution, highly faceted outlines, and uniform spacing between the nanoparticles..$^{32,33}$ Interestingly, in the present study, we observed generally similar evolutions using the $40 \mathrm{~nm}$ selenium nanoparticle solution. After the $40 \mathrm{~nm}$ selenium nanoparticle solution was subjected to 1 hour of heat treatment at $90^{\circ} \mathrm{C}$, the enlarged nanoparticles displayed obvious alterations of shape and homogeneity in comparison with the precursor nanoparticles (Figure 4A and B). Three typical morphological features were evident: first, a much narrower size distribution; second, the predominance of faceted particles with pentagon or hexagon outlines exhibiting three-dimensional profiles; and third, uniform edge-to-edge distances. 

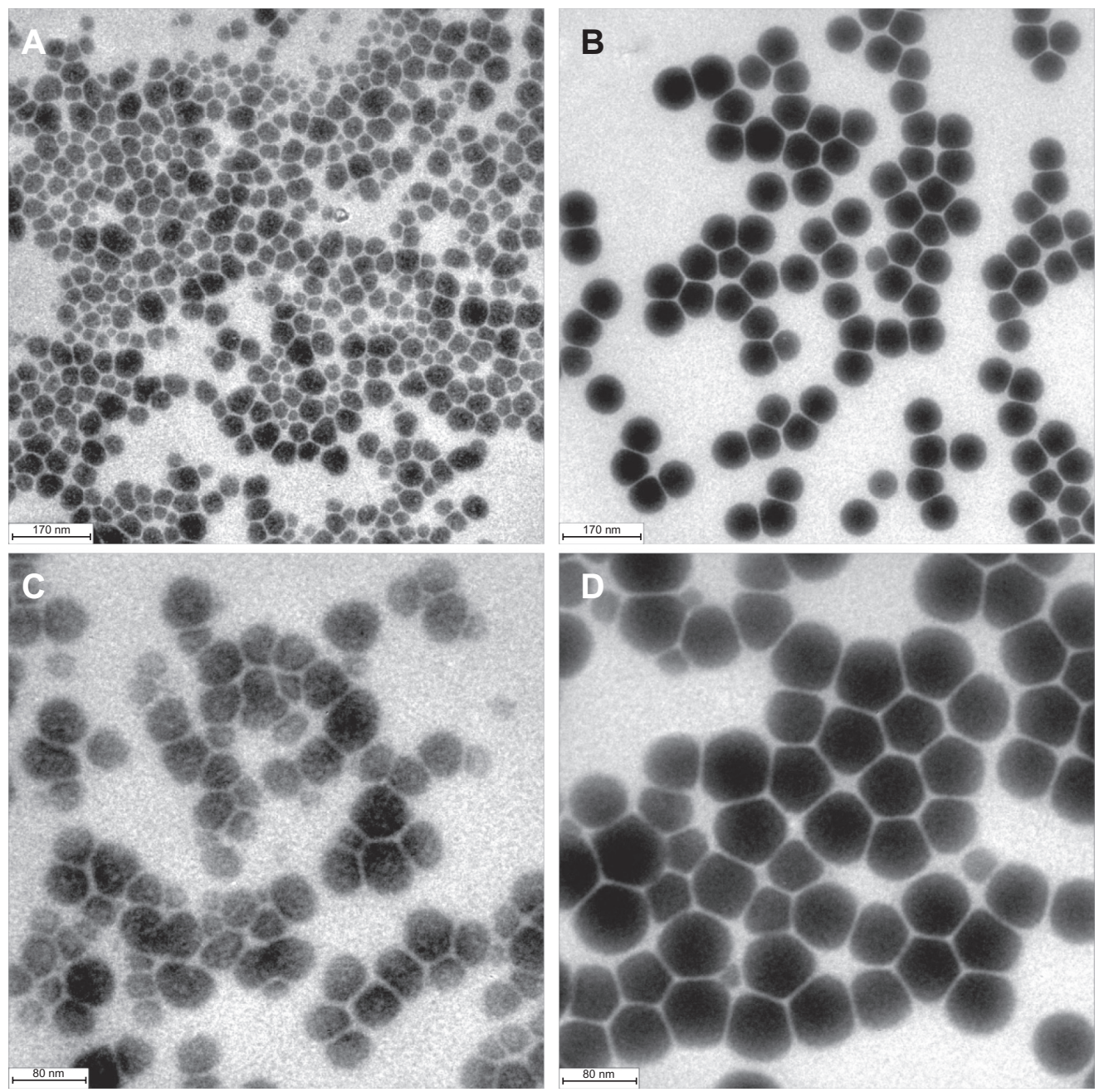

Figure 4 Heat treatment changes the morphology of $40 \mathrm{~nm}$ selenium nanoparticles. (A) and (C) Unheated precursor selenium nanoparticles. (B) and (D) Precursor selenium nanoparticle solution after heating at $90^{\circ} \mathrm{C}$ for one hour.

Note: The bar in $\mathbf{A}$ and $\mathbf{B}$ represents $170 \mathrm{~nm}$, and in $\mathbf{C}$ and $\mathbf{D}$ represents $80 \mathrm{~nm}$.

However, the evolution of the $80 \mathrm{~nm}$ selenium nanoparticles on heat treatment was radical, with both faceted nanoparticles and nanorods being formed after 1 hour of heat treatment at $90^{\circ} \mathrm{C}$ (Figure 1B). Faceted nanoparticles may evolve, as with the $40 \mathrm{~nm}$ selenium nanoparticles, from the smaller $45 \mathrm{~nm}$ nanoparticles that are still present in the $90 \mathrm{~nm}$ selenium nanoparticles (Figure 1A), whereas the nanorods may evolve from the larger $95 \mathrm{~nm}$ nanoparticles in the $90 \mathrm{~nm}$ selenium nanoparticles (Figure 1A). Because bovine serum albumin concentration in the $80 \mathrm{~nm}$ selenium nanoparticles is 10 -fold lower than that in the $40 \mathrm{~nm}$ selenium nanoparticles, it may be argued that the extra protein may prevent the formation of nanorods. However, this possibility was ruled out, because when we added bovine serum albumin to preformed $80 \mathrm{~nm}$ selenium nanoparticles at the same bovine serum albumin concentration as that in the $40 \mathrm{~nm}$ selenium nanoparticles, we found heat treatment at $90^{\circ} \mathrm{C}$ still resulted in formation of nanorods. Thus, the thermally-activated size and structure evolutions are considered to be dependent on precursor particle size, with smaller selenium nanoparticles being more resistant than larger selenium nanoparticles to transformation into nanorods during heat treatment.

In the present study, we only investigated the impact of heat treatment on bioactivity of the $80 \mathrm{~nm}$ selenium nanoparticles, without addressing the issue using the $40 \mathrm{~nm}$ selenium nanoparticles. This selection was based on two reasons. First, the bioactivity of nanorods generated from the $80 \mathrm{~nm}$ selenium nanoparticles is completely unknown. Second, we have elucidated size effects of selenium nanoparticles in vitro, in a cell model, and in vivo, using different sizes ranging from $10 \mathrm{~nm}$ to $200 \mathrm{~nm},{ }^{40,47,48}$ and the sizes of both the precursor $44 \mathrm{~nm}$ selenium nanoparticles and the heated material fall into this range. Our previous studies have demonstrated that different sizes of 
selenium nanoparticles have no differences in bioavailability in both a cell model and in an in vivo model, ${ }^{47}$ but selenium nanoparticles of small size gain advantages in their ability to scavenge multiple free radical species in vitro, ${ }^{48}$ and to enhance selenium accumulation and glutathione S-transferase activity in vivo, ${ }^{40}$ as summarized in Tables 1 and 2 . Based on these studies, it can be inferred that transformation into nanorods is responsible for the observed reduction in bioavailability, and that heat treatment to the $44 \mathrm{~nm}$ selenium nanoparticles would reduce its bioactivity, other than bioavailability.

As a novel supplemental agent with a reduced risk of selenium toxicity, selenium nanoparticle solution may be added to functional foods, for which the final products could require heat processing. The present results suggest that temperature and duration of heat processing, as well as original nanoparticle size, should be carefully selected when a selenium nanoparticle solution is added to functional foods, in order to conserve fully the bioactivity of the selenium nanoparticles. A selenium nanoparticle solution after heat treatment can be monitored for alterations in the size and structure of the nanoparticles, in addition to changes in nutritional parameters/ biomarkers. Normally, selenium is supplemented in food at very low levels; it is not possible to observe selenium nanoparticles by transmission electron microscopy in foods at such low concentrations. Thus, the results obtained from studies of selenium nanoparticle solution as a surrogate for actual foods not only indicate alterations in nutritional parameters,

Table I Comparison of bioactivity of selenium nanoparticles with different sizes in vitro and in vivo at nutritional levels (small 5-15 nm, medium 20-60 nm, large 80-200 nm)

\begin{tabular}{lll}
\hline In vitro and in vivo models & Size effects & Reference \\
\hline \multicolumn{2}{l}{ In vitro models by ESR spectra detection } \\
Scavenging AAPH-generated radical & $\mathrm{S}>\mathrm{M}>\mathrm{L}$ & 48 \\
Scavenging DPPH radical & $\mathrm{S}>\mathrm{M}>\mathrm{L}$ & 48 \\
Scavenging superoxide radical & $\mathrm{S}>\mathrm{M}=\mathrm{L}$ & 48 \\
Scavenging singlet oxygen & $\mathrm{M}>\mathrm{L}$ & 48 \\
Attenuating Cu' ${ }^{2+}$-induced & $\mathrm{S}>\mathrm{M}>\mathrm{L}$ & 48 \\
DNA damage & & \\
HepG2 cells & & \\
Increasing GPx activity & $\mathrm{S}=\mathrm{M}=\mathrm{L}$ & 47 \\
Increasing PHGPx activity & $\mathrm{S}=\mathrm{M}=\mathrm{L}$ & 47 \\
Increasing TrxR activity & $\mathrm{S}=\mathrm{M}=\mathrm{L}$ & 47 \\
Selenium-deficient mice & & \\
Increasing hepatic selenium & $\mathrm{S}=\mathrm{M}=\mathrm{L}$ & 47 \\
Increasing hepatic GPx activity & $\mathrm{S}=\mathrm{M}=\mathrm{L}$ & 47 \\
Increasing hepatic TrxR activity & $\mathrm{S}=\mathrm{M}=\mathrm{L}$ & 47 \\
\hline
\end{tabular}

Abbreviations: ESR, electron spin resonance; AAPH, 2,2'-azo-bis-(2amidinopropane) hydrochloride; DPPH, I,I-diphenyl-2-picryhydrazyl; GPx, glutathione peroxidase; PHGPx, phospholipid hydroperoxide glutathione peroxidase; TrxR, thioredoxin reductase; S, small; M, medium; L, large.
Table 2 Comparison of bioactivity of $36 \mathrm{~nm}$ and $90 \mathrm{~nm}$ selenium nanoparticles at supranutritional levels

\begin{tabular}{|c|c|c|}
\hline $\begin{array}{l}\text { Oral selenium } \\
\text { nanoparticle doses in mice }\end{array}$ & $\begin{array}{l}\text { Size effects in term } \\
\text { of increase }\end{array}$ & Reference \\
\hline $0.5 \mathrm{mg} / \mathrm{kg}$ for 7 days & $\begin{array}{l}\text { Blood selenium } \\
36 \mathrm{~nm}>90 \mathrm{~nm}\end{array}$ & 40 \\
\hline $0.5 \mathrm{mg} / \mathrm{kg}$ for 7 days & $\begin{array}{l}\text { Hepatic GST activity } \\
36 \mathrm{~nm}>90 \mathrm{~nm}\end{array}$ & 40 \\
\hline $2 \mathrm{mg} / \mathrm{kg}$ for 7 days & $\begin{array}{l}\text { Blood selenium } \\
36 \mathrm{~nm}>90 \mathrm{~nm}\end{array}$ & 40 \\
\hline $2 \mathrm{mg} / \mathrm{kg}$ for 7 days & $\begin{array}{l}\text { Hepatic selenium } \\
36 \mathrm{~nm}>90 \mathrm{~nm}\end{array}$ & 40 \\
\hline $2 \mathrm{mg} / \mathrm{kg}$ for 7 days & $\begin{array}{l}\text { Hepatic GST activity } \\
36 \mathrm{~nm}>90 \mathrm{~nm}\end{array}$ & 40 \\
\hline $\begin{array}{l}5 \text { or } 10 \mathrm{mg} / \mathrm{kg} \text { once, } \\
\text { monitored at } 24 \text { or } 72 \text { hours }\end{array}$ & $\begin{array}{l}\text { Blood selenium } \\
36 \mathrm{~nm}>90 \mathrm{~nm}\end{array}$ & 40 \\
\hline $\begin{array}{l}5 \text { or } 10 \mathrm{mg} / \mathrm{kg} \text { once, } \\
\text { monitored at } 24 \text { or } 72 \text { hours }\end{array}$ & $\begin{array}{l}\text { Hepatic selenium } \\
36 \mathrm{~nm}>90 \mathrm{~nm}\end{array}$ & 40 \\
\hline $\begin{array}{l}5 \text { or } 10 \mathrm{mg} / \mathrm{kg} \text { once, } \\
\text { monitored at } 72 \text { hours }\end{array}$ & $\begin{array}{l}\text { Hepatic GST activity } \\
36 \mathrm{~nm}>90 \mathrm{~nm}\end{array}$ & 40 \\
\hline
\end{tabular}

Abbreviation: GST, glutathione.

but also link the alterations to changes in nanoscale size and structure. In addition, different foods would be processed by various types of heat treatment; we cannot address all the possible specific food processes in the present study. However, the results obtained using the selenium nanoparticle solution as a model can justify the general guideline that caution should be used when selenium nanoparticles are added to foods which need to be heated during processing. Based on the results of the present study, in regard to food that has been supplemented with selenium nanoparticles, the best general method for drying would be lyophilization. Given that the thermostability of selenium nanoparticles is size-dependent, smaller selenium nanoparticles being more resistant than larger selenium nanoparticles to transformation into nanorods during heat treatment, there is also the strong implication that the use of smaller size selenium nanoparticles in foods is essential if extensive heat exposure is unavoidable. On the other hand, some food heat processes involve lower temperature conditions than those required to affect selenium nanoparticle structure and bioavailability. For example, to prepare selenium capsules, $1 \mathrm{~mL}$ selenium nanoparticle solution $(400 \mu \mathrm{g} / \mathrm{mL})$ is added to $2 \mathrm{~g}$ starch, and this mixture could be dried at $60^{\circ} \mathrm{C}$ for 40 minutes with an airblast. Milk sterilization involves heat treatment at $62^{\circ} \mathrm{C}$ for 30 minutes. To mimic these processes, we observed the impact of heat treatment at $60^{\circ} \mathrm{C}$ for 40 minutes on a $31 \mathrm{~nm}$ selenium nanoparticle solution. As shown in Supplementary Figure 1, such a moderate heat process did not alter the size of the selenium nanoparticles. Thus, as 
compared with the use of inorganic selenium salts (where heat is not a consideration), the potential disadvantages of using selenium nanoparticles when a heat process is required can potentially be overcome, provided nanoscale size and heat treatment conditions are carefully selected.

\section{Conclusion}

Heat treatment has a significant impact on the size, structure, and bioactivity of selenium nanoparticles. In general, the sizes of selenium nanoparticles increase and bioactivities decrease when a selenium nanoparticle solution is subjected to heat treatment. However, the thermally-activated size and structure evolution are substantially dependent upon precursor particle size, with smaller selenium nanoparticles being more resistant than larger selenium nanoparticles to transformation into nanorods during heat treatment.

\section{Acknowledgments}

This work was supported by the National Natural Science Foundation of China (grant 31170648 to JZ), the National Basic Research Program of China (973 Program, grant 2009CB930204), and by a grant from Anhui Agricultural University to $\mathrm{JZ}$.

\section{Disclosure}

The authors have no financial conflict of interest in this work.

\section{References}

1. Steinbrenner H, Sies H. Protection against reactive oxygen species by selenoproteins. Biochim Biophys Acta. 2009;1790:1478-1485.

2. Brigelius-Flohé R. Tissue-specific functions of individual glutathione peroxidases. Free Radic Biol Med. 1999;27:951-965.

3. Arnér ES. Focus on mammalian thioredoxin reductases - important selenoproteins with versatile functions. Biochim Biophys Acta. 2009; 1790:495-526.

4. Méplan C, Hughes DJ, Pardini B, et al. Genetic variants in selenoprotein genes increase risk of colorectal cancer. Carcinogenesis. 2010;31: 1074-1079.

5. Peters U, Chatterjee N, Hayes RB, et al. Variation in the selenoenzyme genes and risk of advanced distal colorectal adenoma. Cancer Epidemiol Biomarkers Prev. 2008;17:1144-1154.

6. Diwadkar-Navsariwala V, Prins GS, Swanson SM, et al. Selenoprotein deficiency accelerates prostate carcinogenesis in a transgenic model. Proc Natl Acad Sci U S A. 2006;103:8179-8184.

7. Irons R, Carlson BA, Hatfield DL, Davis CD. Both selenoproteins and low molecular weight selenocompounds reduce colon cancer risk in mice with genetically impaired selenoprotein expression. $J$ Nutr. 2006;136: 1311-1317.

8. Rayman MP. Selenium in cancer prevention: a review of the evidence and mechanism of action. Proc Nutr Soc. 2005;64:527-542.

9. El-Bayoumy K. The protective role of selenium on genetic damage and on cancer. Mutat Res. 2001;475:123-139.

10. Kowalska E, Narod SA, Huzarski T, et al. Increased rates of chromosome breakage in BRCA1 carriers are normalized by oral selenium supplementation. Cancer Epidemiol Biomarkers Prev. 2005;14: 1302-1306.
11. Xiao H, Parkin KL. Induction of phase II enzyme activity by various selenium compounds. Nutr Cancer. 2006;55:210-223.

12. El-Sayed WM, Aboul-Fadl T, Lamb JG, Roberts JC, Franklin MR. Effect of selenium-containing compounds on hepatic chemoprotective enzymes in mice. Toxicology. 2006;220:179-188.

13. El-Sayed WM, Aboul-Fadl T, Roberts JC, Lamb JG, Franklin MR. Murine hepatoma (Hepa1c1c7) cells: a responsive in vitro system for chemoprotective enzyme induction by organoselenium compounds. Toxicol In Vitro. 2007;21:157-164.

14. 't Hoen PA, Rooseboom M, Bijsterbosch MK, van Berkel TJ, Vermeulen NP, Commandeur JN. Induction of glutathione-S-transferase mRNA levels by chemopreventive selenocysteine Se-conjugates. Biochem Pharmacol. 2002;63:1843-1849.

15. Prokopczyk B, Rosa JG, Desai D, et al. Chemoprevention of lung tumorigenesis induced by a mixture of benzo(a)pyrene and 4-(methylnitrosamino)-1-(3-pyridyl)-1-butanone by the organoselenium compound 1,4-phenylenebis(methylene)selenocyanate. Cancer Lett. 2000;161:35-46.

16. Ip C. Lessons from basic research in selenium and cancer prevention. J Nutr. 1998;128:1845-1854.

17. Whanger PD. Selenium and its relationship to cancer: an update. $B r J$ Nutr. 2004;91:11-28.

18. Combs GF Jr, Garbisu C, Yee BC, et al. Bioavailability of selenium accumulated by selenite-reducing bacteria. Biol Trace Elem Res. 1996;52:209-225.

19. Ganther HE. Selenotrisulfides. Formation by the reaction of thiols with selenious acid. Biochemistry. 1968;7:2898-2905.

20. Zhang JS, Gao XY, Zhang LD, Bao YP. Biological effects of a nano red elemental selenium. Biofactors. 2001;15:27-38.

21. Wang $\mathrm{H}$, Zhang J, Yu H. Elemental selenium at nano size possesses lower toxicity without compromising the fundamental effect on selenoenzymes: comparison with selenomethionine in mice. Free Radic Biol Med. 2007;42:1524-1533.

22. Zhang J, Wang X, Xu T. Elemental selenium at nano size (Nano-Se) as a potential chemopreventive agent with reduced risk of selenium toxicity: comparison with se-methylselenocysteine in mice. Toxicol Sci. 2008;101:22-31.

23. Zhang J, Wang H, Yan X, Zhang L. Comparison of short-term toxicity between Nano-Se and selenite in mice. Life Sci. 2005;76:1099-1109.

24. Jia X, Li N, Chen J. A subchronic toxicity study of elemental Nano-Se in Sprague-Dawley rats. Life Sci. 2005;76:1989-2003.

25. Zhang J, Wang H, Peng D, Taylor EW. Further insight into the impact of sodium selenite on selenoenzymes: high-dose selenite enhances hepatic thioredoxin reductase 1 activity as a consequence of liver injury. Toxicol Lett. 2008;176:223-229.

26. Kong L, Yuan Q, Zhu H, et al. The suppression of prostate LNCaP cancer cells growth by Selenium nanoparticles through Akt/Mdm2/ AR controlled apoptosis. Biomaterials. 2011;32:6515-6522.

27. Tran PA, Webster TJ. Nanotechnologies for cancer diagnostics and treatment. In: Dixon CJ, Curtines OW, editors. Nanotechnology: Nanofabrication, Patterning, and Self Assembly. New York, NY: Nova Science Publishers; 2011.

28. Tran PA, Webster TJ. Selenium nanoparticles inhibit Staphylococcus aureus growth. Int J Nanomedicine. 2011;6:1553-1558.

29. Zhang J, Spallholz J. Toxicity of selenium compounds and nano-selenium particles. In: Casciano D, Sahu SC, editors. Handbook of Systems Toxicology. West Sussex, UK: John Wiley and Sons; 2011.

30. Zhang J. Biological properties of red elemental selenium at nano size (Nano-Se) in vitro and in vivo. In: Sahu SC, Casciano D, editors. Nanotoxicity: From In Vivo and In Vitro Model To Health Risks. West Sussex, UK: John Wiley and Sons; 2009.

31. Kara A, Rahman TS. Vibrational dynamics and thermodynamics of surfaces and nanostructures. Surf Sci Rep. 2005;56:159-187.

32. Maye MM, Zheng W, Leibowitz FL, Ly NK, Zhong CJ. Heatinginduced evolution of thiolate-encapsulated gold nanoparticles: A strategy for size and shape manipulations. Langmuir. 2000;16: $490-497$. 
33. Maye MM, Zhong CJ. Manipulating core-shell reactivities for processing nanoparticle sizes and shapes. J Mater Chem. 2000;10:1895-1901.

34. Bradford MM. A rapid and sensitive method for the quantitation of microgram quantities of protein utilizing the principle of protein-dye binding. Anal Biochem. 1976;72:248-254.

35. Rotruck JT, Pope AL, Ganther HE, Swanson AB, Hafeman DG, Hoekstra WG. Selenium: biochemical role as a component of glutathione peroxidase. Science. 1973;179:588-590.

36. Habig WH, Pabst MJ, Jakoby WB. Glutathione S-transferases. The first enzymatic step in mercapturic acid formation. J Biol Chem. 1974;249:7130-7139.

37. Holmgren A, Björnstedt M. Thioredoxin and thioredoxin reductase. Methods Enzymol. 1995;252:199-208.

38. Ganther H, Ip C. Thioredoxin reductase activity in rat liver is not affected by supranutritional levels of monomethylated selenium in vivo and is inhibited only by high levels of selenium in vitro. J Nutr. 2001;131:301-304.

39. Olson OE, Palmer IS, Cary EE. Modification of the official fluorometric method for selenium in plants. J Assoc Off Anal Chem. 1975;58:117-121.

40. Peng D, Zhang J, Liu Q, Taylor EW. Size effect of elemental selenium nanoparticles (Nano-Se) at supranutritional levels on selenium accumulation and glutathione S-transferase activity. J Inorg Biochem. 2007;101:1457-1463.
41. Oremland RS, Herbel MJ, Blum JS, et al. Structural and spectral features of selenium nanospheres produced by Se-respiring bacteria. Appl Environ Microbiol. 2004;70:52-60.

42. Mishra RR, Prajapati S, Das J, Dangar TK, Das N, Thatoi H. Reduction of selenite to red elemental selenium by moderately halotolerant Bacillus megaterium strains isolated from Bhitarkanika mangrove soil and characterization of reduced product. Chemosphere. 2011;84:1231-1237.

43. Debieux CM, Dridge EJ, Mueller CM, et al. A bacterial process for selenium nanosphere assembly. Proc Natl Acad Sci U S A. 2011;108:13480-13485.

44. Mishra B, Hassan PA, Priyadarsini KI, Mohan H. Reactions of biological oxidants with selenourea: formation of redox active nanoselenium. J Phys Chem B. 2005;109:12718-12723.

45. Dobias J, Suvorova EI, Bernier-Latmani R. Role of proteins in controlling selenium nanoparticle size. Nanotechnology. 2011;22:195605.

46. Zhang Y, Wang J, Zhang L. Creation of highly stable selenium nanoparticles capped with hyperbranched polysaccharide in water. Langmuir. 2010;26:17617-17623.

47. Zhang J, Wang H, Bao Y, Zhang L. Nano red elemental selenium has no size effect in the induction of seleno-enzymes in both cultured cells and mice. Life Sci. 2004;75:237-244.

48. Huang B, Zhang J, Hou J, Chen C. Free radical scavenging efficiency of Nano-Se in vitro. Free Radic Biol Med. 2003;35:805-813. 


\section{Supplementary material}
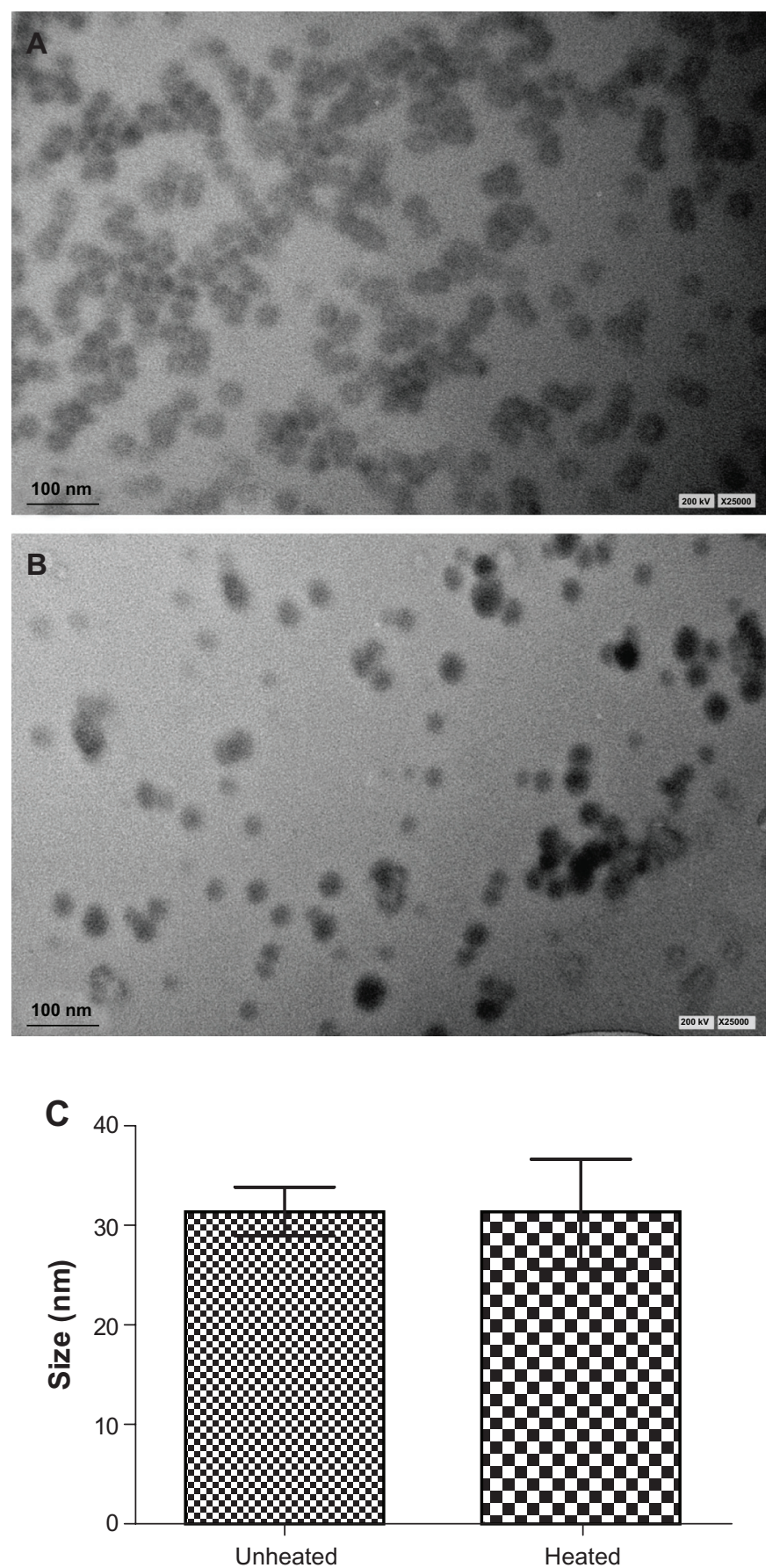

Figure SI Impact of heat treatment on size and structure of $31 \mathrm{~nm}$ selenium nanoparticles. (A) Unheated precursor selenium nanoparticles. (B) Precursor selenium nanoparticle solution after heating at $60^{\circ} \mathrm{C}$ for 40 minutes. (C) Size before and after heat treatment.

Note: Data are presented as the mean \pm standard deviation $(n=70)$.

International Journal of Nanomedicine

\section{Publish your work in this journal}

The International Journal of Nanomedicine is an international, peerreviewed journal focusing on the application of nanotechnology in diagnostics, therapeutics, and drug delivery systems throughou the biomedical field. This journal is indexed on PubMed Central, MedLine, CAS, SciSearch ${ }^{\circledR}$, Current Contents ${ }^{\circledR} /$ Clinical Medicine,

\section{Dovepress}

Journal Citation Reports/Science Edition, EMBase, Scopus and the Elsevier Bibliographic databases. The manuscript management system is completely online and includes a very quick and fair peer-review system, which is all easy to use. Visit http://www.dovepress.com/ testimonials.php to read real quotes from published authors.

Submit your manuscript here: http://www.dovepress.com/international-journal-of-nanomedicine-journal 